Supplement of Biogeosciences, 14, 3669-3683, 2017

https://doi.org/10.5194/bg-14-3669-2017-supplement

(C) Author(s) 2017. This work is distributed under

the Creative Commons Attribution 3.0 License.

(c) (1)

Supplement of

\title{
Seasonal variability in methane and nitrous oxide fluxes from tropical peatlands in the western Amazon basin
}

Yit Arn Teh et al.

Correspondence to: Yit Arn Teh (yateh@abdn.ac.uk)

The copyright of individual parts of the supplement might differ from the CC BY 3.0 License. 


\section{Figure Captions}

Figure S1. Scatter plot of soil temperature against diffusive $\mathrm{CH}_{4}$ flux. The data presented here are not transformed. Statistical analysis was performed on Box-Cox transformed data $\left(P<0.004481, r^{2}=0.0356, n=986\right)$.

Figure S2. Scatter plot of water table depth against diffusive $\mathrm{CH}_{4}$ flux. The data presented here are not transformed. Statistical analysis was performed on Box-Cox transformed data $\left(P<0.000097, r^{2}=0.75, n=987\right)$.

Figure S3. Scatter plot of dissolved oxygen against diffusive $\mathrm{N}_{2} \mathrm{O}$ flux. The data presented here are not transformed. Statistical analysis was performed on Box-Cox transformed data $\left(P>0.9498, r^{2}=0.000003638, n=1091\right)$.

Figure S4. Scatter plot of electrical conductivity against diffusive $\mathrm{N}_{2} \mathrm{O}$ flux. The data presented here are not transformed. Statistical analysis was performed on Box-Cox transformed data $\left(P<0.0498, r^{2}=0.003528, n=1087\right)$. 
Figure S1

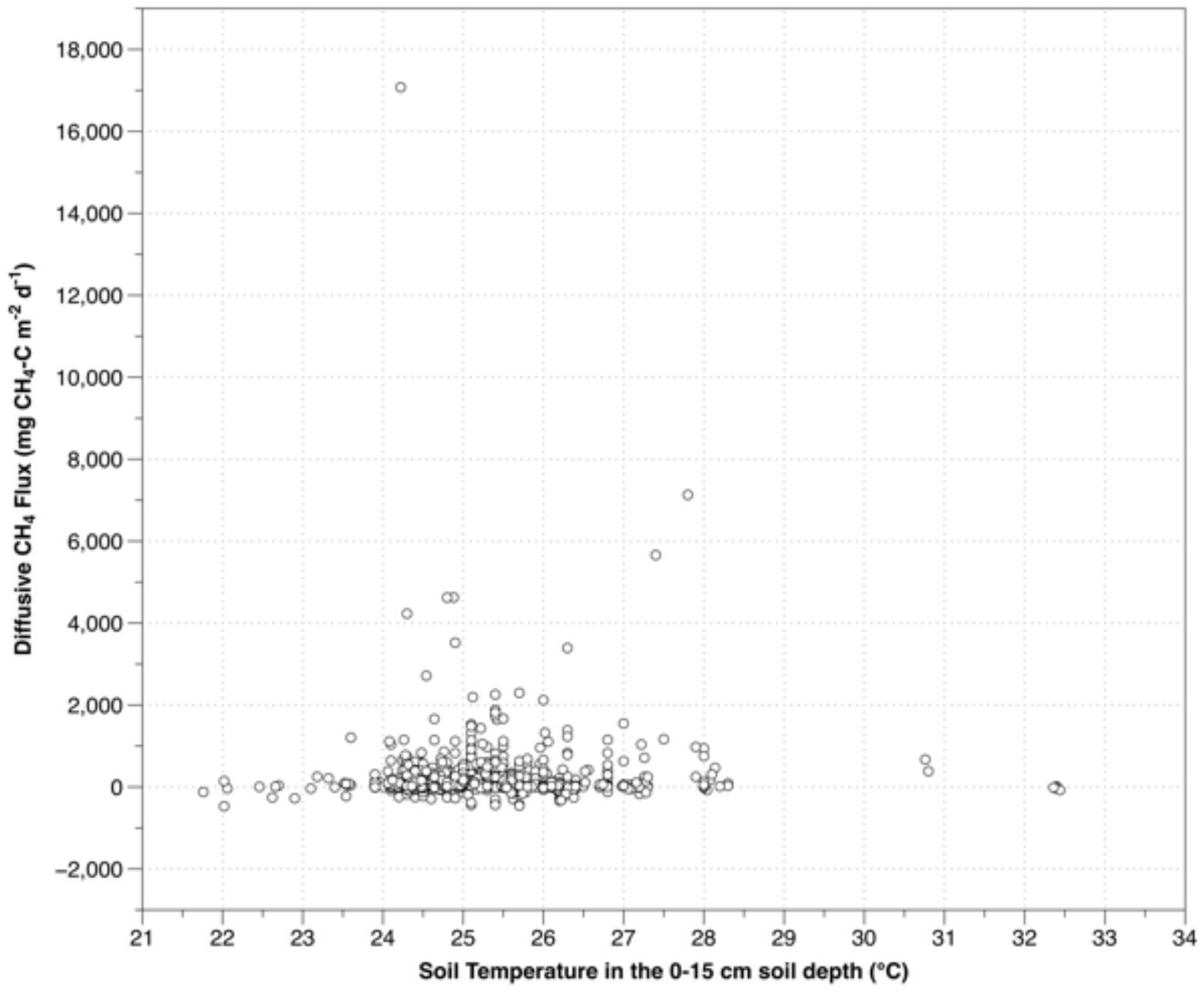


Figure S2

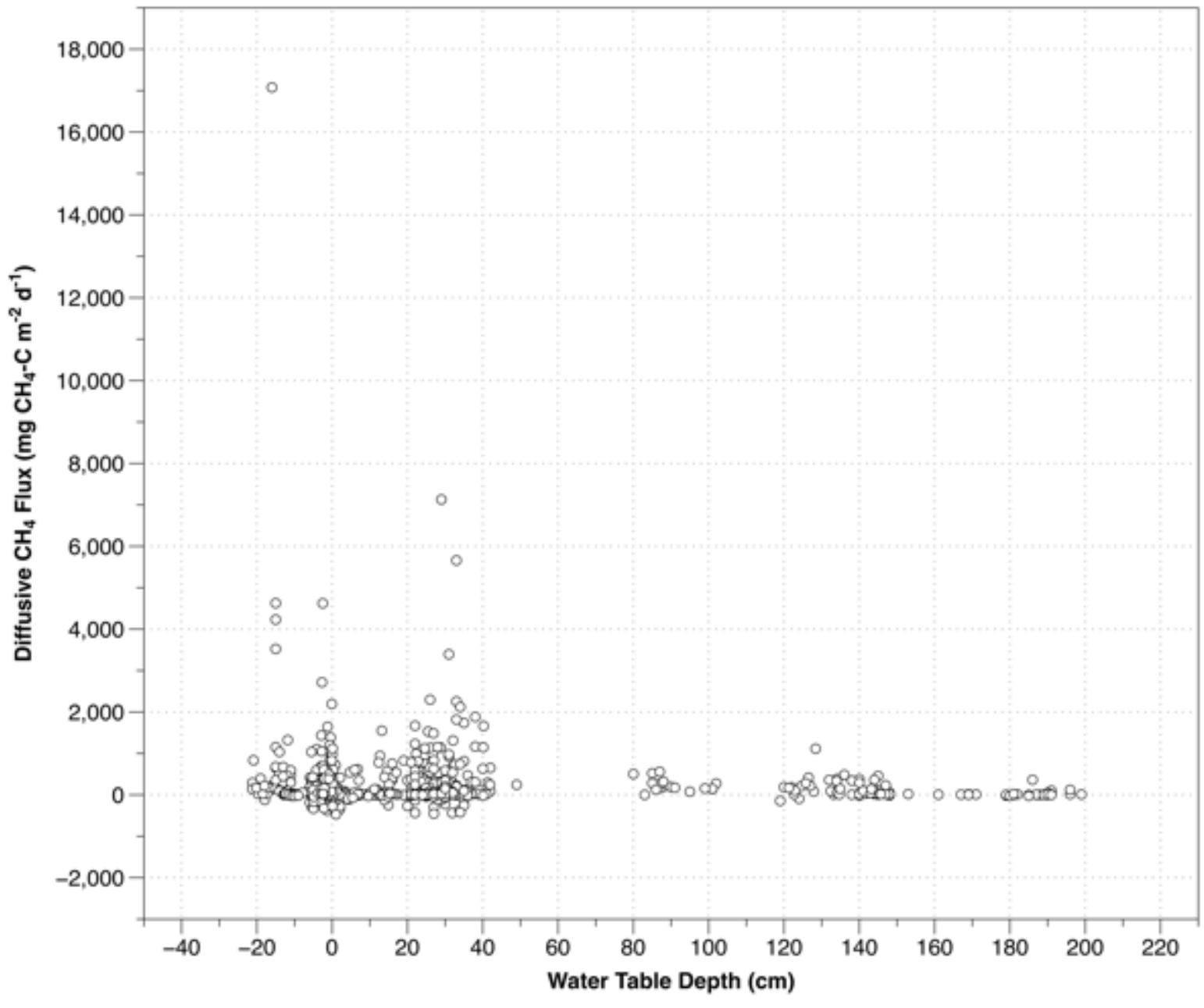


Figure S3

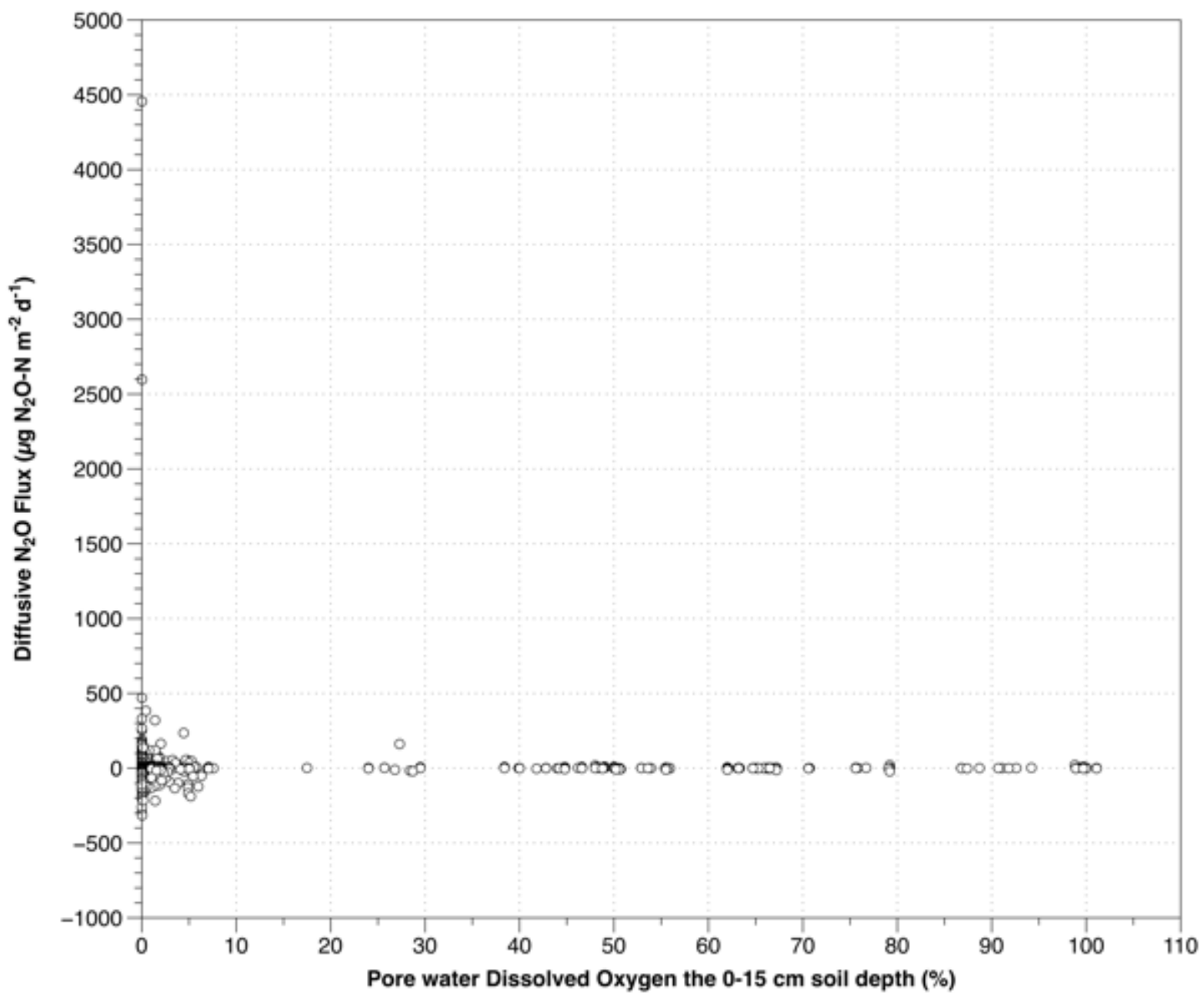


Figure S4

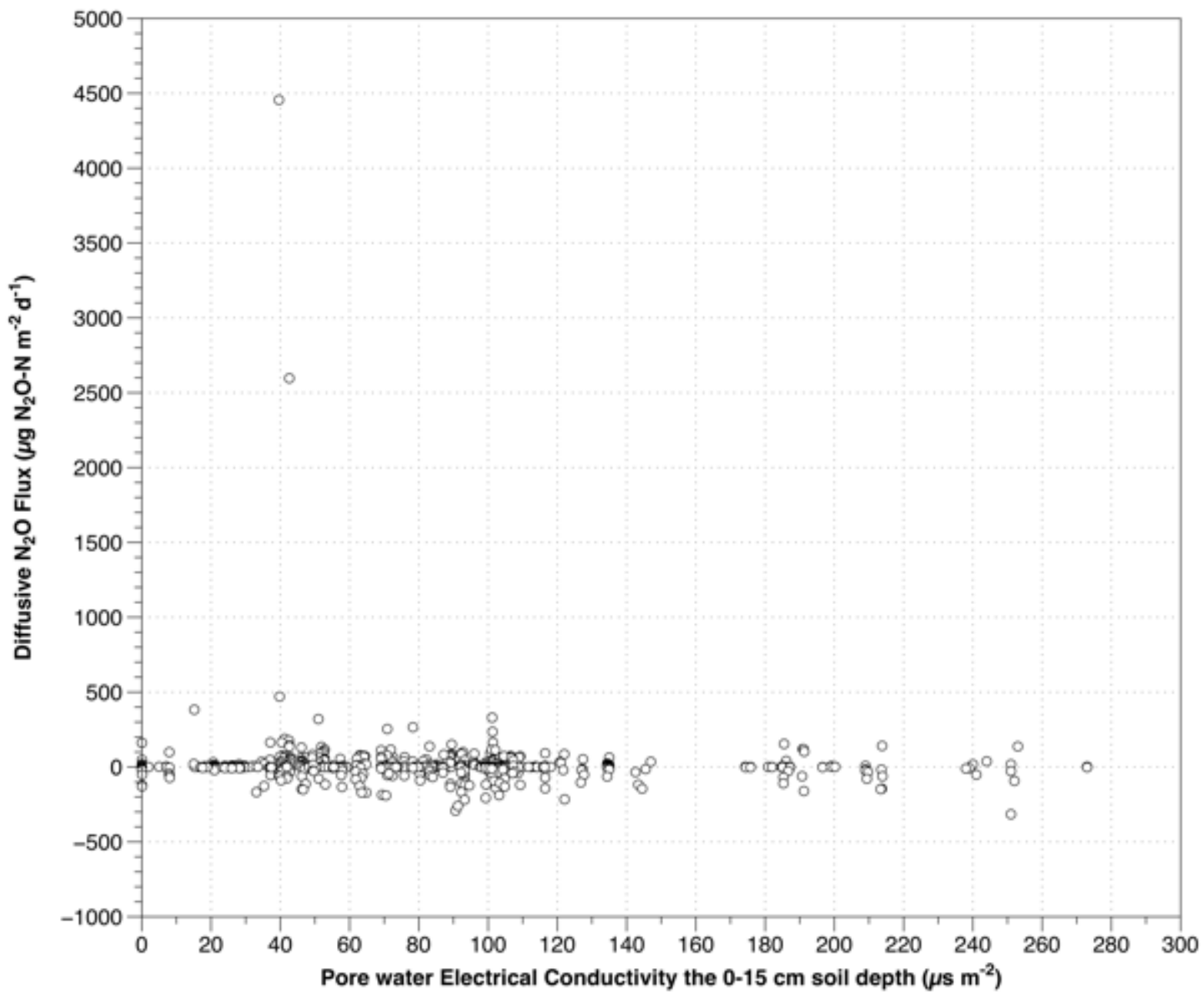

